\title{
Venetian blinds as a version of sun- shelves to be used in hot and sunny climate conditions
}

\author{
Sergey Stetsky ${ }^{1, *}$ and Lyubov Gnedina ${ }^{1}$ \\ ${ }^{1}$ Moscow State University of Civil Engineering, Yaroslavskoeshosse, 26, Moscow, 129337, Russia
}

\begin{abstract}
Light-shelves, as a mean to distribute sun-ray's flows, can be considered as a minor parts of venetian blinds. Light shelves, acting as light- spreading devices, spread sun light rays, transformed into diffuse light flows into the depth of a promise. The same function possesplanks of venetian blinds, though they have a much less geometry sizes. The aim of the investigations presented is to determine the optimum size of these planks and distance between them in order to ensure a maximum natural lighting of interiors under different sort of lighting, which is associated with different climatic regions or with different seasons of a year. The proposed solutions allow reducing electric power consumption in buildings.
\end{abstract}

\section{Introduction}

Light-shelves, acting as a sun - protecting devices (SPD) along with its light-reflective and light-spreading functions in form of light-spreading devices (LSD; or light-shelves) proved their functional efficiency in number of theoretical and case field studies [1$3,5,6,9,12-15]$.

But at the same time, traditional LSDareenormously large in size, and this fact makes the use of these elements not convenient from the ergonomicall point of view.

Hence, the appropriate solution of this problem can be the use of a LSD not in form of single and wide light-shelf, but in form of a multi-shelves devices with much less width and increased number of horizontal planks, what makes them resembling a traditional form of venetian blinds. It is a theoretical suggestion of this article and the content of the work presented is going to prove the rightness of this assumption.

\section{Theoretical background}

In former scientific investigations a number of positive characteristics of "SPD" and "LSD" as regards to natural illumination of interiors or lowering overheating of promises due to extra sun radiation penetrated indoors were shown [10,11,16,17,18]. Moreover,in these works, the optimum position and sizes of the devices in question were determined. But, due to the novation of the problem considered, these conclusions cannot be considered as the final and complete ones. The new points to be studied are as follows:

\footnotetext{
*Corresponding author: sergioni1947@gmail.com
} 
1. The ergonomic aspect of LSD structures as regards their sizes and distance of projection indoors or outdoors

2. The lighting ability of LSD due to their reflecting properties;

3. The optimum spacing of a LSD planks which may makes them more similar to "venetian blinds", rather than a traditional "light shelves", which are usually big in sizes and few in number.

As a result of studies, which were conducted recently in the "Design of buildings and structures" Chair of Moscow State University of Civil Engineering, a new design offer was elaborated (see Figures 1 and 2).

The studies were not of universal character, as they took into account only SPD/LSD units, fixed in the window opening.( 1.e. "Stationary units"), with

southern aspect of orientation. Such a situation is most frequent for sun protection devices under clear sky conditions in regions with hot and sunny climate.

In these studies, that authors took into account the need not only to protect the interiors of building from uncomfortable overheating due to the excessive solar radiation, but also the need to supply the interiors with sufficient amount of anatural light. The first problem is to be solved with sun-protection and the second - with light reflection and spreading of light flows.

Hence, the combined functional use of newly-offered units in form of SPD/LSD is quite essential and efficient. Moreover, thestepped position a SPD/LSD planks, as shown in articles $[4,7,8]$ proved low efficiency as regards to natural light supply into the interiors (see Figures 3 and 4)

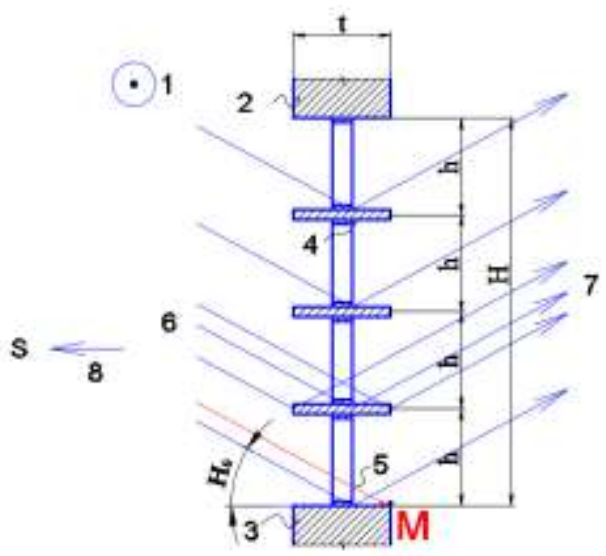

Fig. 1. A design scheme of a window with light shelves, acting as sun-protective and light-spreading devices, where: 1 - a position of the sun under a "clear sky" condition; 2 - a top of a window opening; 3 - a bottom of a window opening; 4 - a SPD/LSD planks; 5 - separate glazed window panes; 6 - light flows from the sun; 7 - reflected light flows; 8 - orientation aspect of the window; 9 "M"- a design point of insolation; $\mathrm{H}$ - an overall height of a window, $\mathrm{h}$ - a spacing of SPD/LSD planks; $\mathrm{t}$ - thickness of a wall and width of planks; $\mathrm{H}_{0}$ - vertical angle of the sun position (sun height).

Sketches on figures 3 and 4 show the stepped position of SPD/LSD planks. Under such a version, these planks loose their multifunctional properties, beaming more sun-protective, than light reflective and light spreading. 


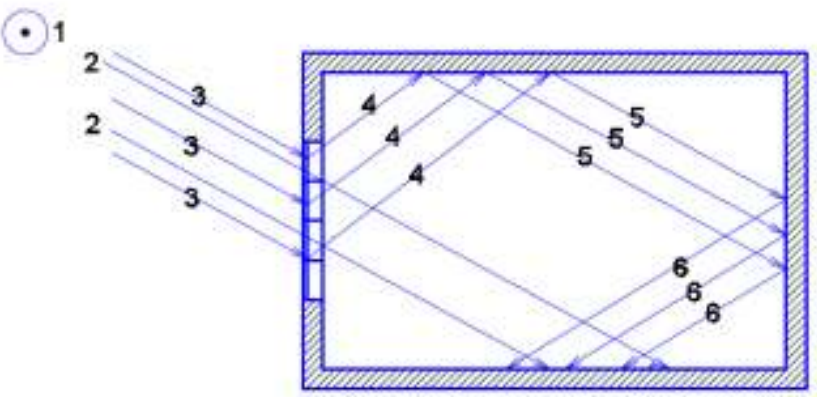

Fig. 2. Light penetration into the interior under"clear sky" conditions and use of SPD/LSD, where: 1 - a position of the sun; 2 - light flows from the sun, directly penetrating into an interior; 3 - light flows from the sun, having a SPD/LSD on their way; 4 - light flows, reflecting from SPD/LSD to a ceiling of a premise; 5 - light flows, reflecting from a ceiling to a rear wall of a premise; 6 - light flows, reflecting from a rear wall to a floor or to a level or working plane.

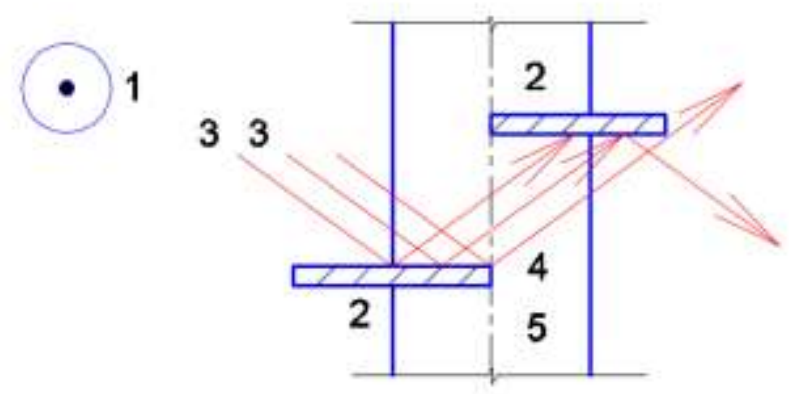

Fig. 3. First version of a stepped SPD/LSD planks position (top to bottom: from inside to outside), where: 1 - the sun; 2 - SPD/LSD planks; 3 - sun rays, blocked by the planks; 4 - sun rays, passed indoors; 5 - window opening in a wall.

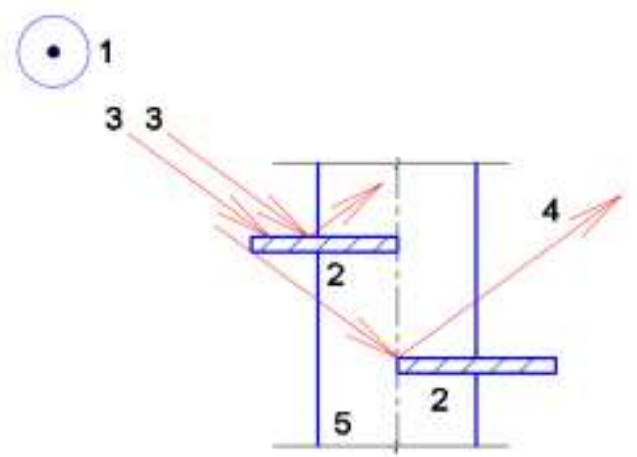

Fig. 4. Second version of a stepped SPD/LSD planks position ( top to bottom from outside to inside), where: 1 - the sun; 2 - SPD/LSD planks; 3 - sun rays, blocked by the planks; 4 - sun rays, passed indoors; 5 - window opening in a wall. 


\section{Design studies}

In the studies presented the examplesof a civil buildings in a southern climatic conditionare examined. The window of the building is of southern aspect of orientation, under which the use of horizontal outdoor SPD are traditional and widely used. We consider the suggested light shelves as a minor type of canopies (awnings). The main characteristics of climate conditions chosen are as follows:

i/ - The sky is clear and sun rays influence is straight, i.e. the outdoor natural illumination is not diffuse;

ii / - The southern regions, close to equator were not considered. Hence, under a low latitudes the role of windows in the process of insolation and sun radiation gains reduces greatly. The reasonable zone for SPD use is from $20^{\circ}$ to $40^{\circ}$ of north or south latitude; $75^{0}$.

iii / - under thelatitudeschoosen, the ordinary sun height in summer period is from $60^{\circ}$ to

Hence, according to sketch on Figure 1, the geometries of horizontal planking within the given window can be expresser as follows:

$$
\operatorname{ctg} \mathrm{H}_{0}=\frac{\mathrm{t}}{\mathrm{h}}
$$

Where all the members of the formula are presented in key, referenced to figure 1 .

As one can see,this expression does not depend on the height or width of a window.

Assuming the " $\mathrm{t}$ " equal to $(30 \mathrm{~cm})$ and $\mathrm{H}_{0}$ range from $60^{\circ}$ to $75^{\circ}$, we can calculate the spacing of horizontal planks as follows:

$$
\mathrm{h}=\frac{\mathrm{t}}{\operatorname{ctg} \mathrm{H}_{0}} ;
$$

The formula (1) should be better used with the known thickness of a wall, which dictates the width of the SPD/LSD planks. In real practice, the width of planks is usually from $50 \%$ to $100 \%$ the thickness of a wall. For the value of $\mathrm{H}_{0}$ equal to $60^{\circ}$, ctg $\mathrm{H}_{0}=0,58$ and $\mathrm{h}_{1}=\frac{30}{0,58}=51,12 \mathrm{~cm}$.

For the value of $\mathrm{H}_{0}$ equal to $75^{\circ}, \operatorname{ctg} \mathrm{H}_{0}=0,27$ and $\mathrm{h}_{2}=\frac{30}{0,27}=111,11 \mathrm{~cm}$.

\section{Conclusions}

1. It is stated, that light- reflecting functions of light shelves (LSD) can be efficiently combined with their sun-protective functions. Hence, the best design solution in this case is designwindow set of horizontal planks, as an average solution between venetian blinds and sun- protective canopies (awnings).

2. It is shown, that reflective functions of the light-shelves (LSD) is mostly aimed on the increase of natural indoor illumination in furthermost design points in a premise to satisfy the normative requirements to daylight factor values.

3. To ensure the comfortable contact with the outdoor environment, the minimum spacing between SPD/LSD planks should not be less than the thickness of an external wall. From the other side, the maximum spacing should not exceed twice the thickness of a wall, to ensure proper sun - protective functions of the system.

\section{Refrences}

1. N.M. Gusev, Fundaments or building physics (Stroyizdat, Moscow, 1975)

2. A.K. Soloviev, Environmental physics (ASV publishers, Moscow, 2008) 
3. S.V. Stetsky, Scientific review 21, 54-58 (2016)

4. K.O. Larionova, A.A. Alekseeva, Scientific Review 12, 48-55 (2017)

5. S.V. Stetsky, PGS 7, 76-80 (2015)

6. S.V. Stetsky, Scientific review 7-2, 572-579 (2014)

7. S.A. Porublev, S.V. Stetsky, MGSU Gerald 4, 34-35 (2011)

8. S.V. Stetsky, S.A. Porublev, Building materials, equipment and technologies of XXI century 4, 34-36 (2011)

9. S.V. Stetsky, V.A. Hodeyr, MGSU Gerald 7, 9-15 (2012)

10. E.L. Harkness, M.L. Mehta, Solar radiation control in Buildings (Stroyizdat, Moscow, 1984)

11. M. Tvarovsky, Sun in architecture (Stroyizdat, Moscow, 1977)

12. O. Smirnova. ARPN Journal of Engineering and Applied Sciences, 14(3), pp.600-610 (2019)

13. S.V. Stetsky, V.A. Hodeyr, MGSU Gerald 8, 39-45 (2012)

14. S.V. Stetsky, M.A. Salo, Building materials, equipment and technologies of XXI century 10, 64 (2004)

15. S.V. Stetsky, H. Amnaz, Building materials, equipment and technologies of XXI century 12, 52 (2004)

16. Blinds and shutters. Thermal and visual comfort. European standard, final draft. (European committee for standardization, Brussel, 2012)

17. Solar shading for low-energy Buildings (European solar shading organization (ESSO), Belgium, 2012)

18. Understanding overheating: where to start. A guide for house builders and designers (NHBC Foundation, Milton Keynes, Great Britain, 2012) 